\title{
Short- to long-term trends in hydrologic drought conditions in the contiguous United States
}

\author{
Peter T. Soulé ${ }^{1}$, Zhi-Yong Yin ${ }^{2}$ \\ ${ }^{1}$ Department of Geography and Planning, Appalachian State University, Boone, North Carolina 28608, USA \\ ${ }^{2}$ Department of Geography, Georgia State University, Atlanta, Georgia 30303, USA
}

\begin{abstract}
Moisture trends are examined for the contiguous United States for recent 15, 30, 50 and 95 yr periods (1895 to 1989) using bivariate linear regression and annual values of the Palmer Hydrologic Drought Index. Linear trend slopes and corresponding p-values from Spearman rank correlations are mapped from a series of regressions to examine the spatial patterns of trends and how they change through time. For each mapped time series there are distinct core regions with strong positive and negative trends. Mean trends for the nation as a whole are positive for the 95, 50, and $30 \mathrm{yr}$ time series, but switch to negative for the most recent 15 yr time series. The perception of climate changing toward either a wetter or drier regime is thus partially a function of temporal scaling
\end{abstract}

KEY WORDS: Hydrological drought · Drought trends · United States

\section{INTRODUCTION}

Research on long-term changes in surface moisture conditions in the contiguous United States within the period 1895 to 1989 has shown there is no clear answer to the question of whether the majority of the country has experienced significant changes toward wetter or drier conditions in the last 90+ yr (Karl \& Heim 1990, Idso \& Balling 1992, Soulé 1993). Karl \& Heim (1990) found significant shifts toward wetter conditions nationally since the mid 1930s, but no significant trends when using data from the entire study period (1895 to 1989). Idso \& Balling (1992, p. 281) found a 'highly statistically significant' change in slope between the 1895-1954 and 1955-1989 periods for the country as a whole, with 38 of 48 states showing a shift toward wetter conditions. Using climatic-division-level data and difference-of-means tests, Soulé (1993) found less compelling evidence for a wholesale shift toward wetter conditions. Analyses between different $45 \mathrm{yr}$ means (1900-1944/1945-1989) showed statistically significant changes $(\alpha=0.05)$ at $39 \%$ of the 344 climatic divisions, with some regions getting drier (e.g. the north central Rocky Mountains) and some getting wetter (e.g. the southeast). When comparing mean moisture conditions among discreet 30 yr periods (1900-1929/1930-1959/1960-1989), Soulé (1993, p. 2369) found 'that just over $50 \%$ of the climatic divisions (173) had no significant change in the moisture status.' While differences in methodologies, data aggregation (e.g. climatic division versus state-level data), and the specific drought index used largely account for the differences in the interpretation of results from these studies, analyses of moisture trends at a finer spatial scale are needed. In this study we expand the previous work on surface moisture trends in the contiguous United States during the 1895 to 1989 period by using climatic-division-level data to examine the spatial patterns of temporal trends in an annual measure of hydrologic drought severity. In addition, we expand the analyses temporally by examining trends over the entire study period and the most recent 15,30, and 50 yr periods. Our guiding research questions are: (1) what are the direction and strength of linear trends in annual drought conditions at each of the 344 climatic divisions in the contiguous United States, (2) what is the degree of regional homogeneity in these trends, and (3) how do the spatial patterns change when different time periods are considered (i.e. complete record versus 30 yr trends)? 


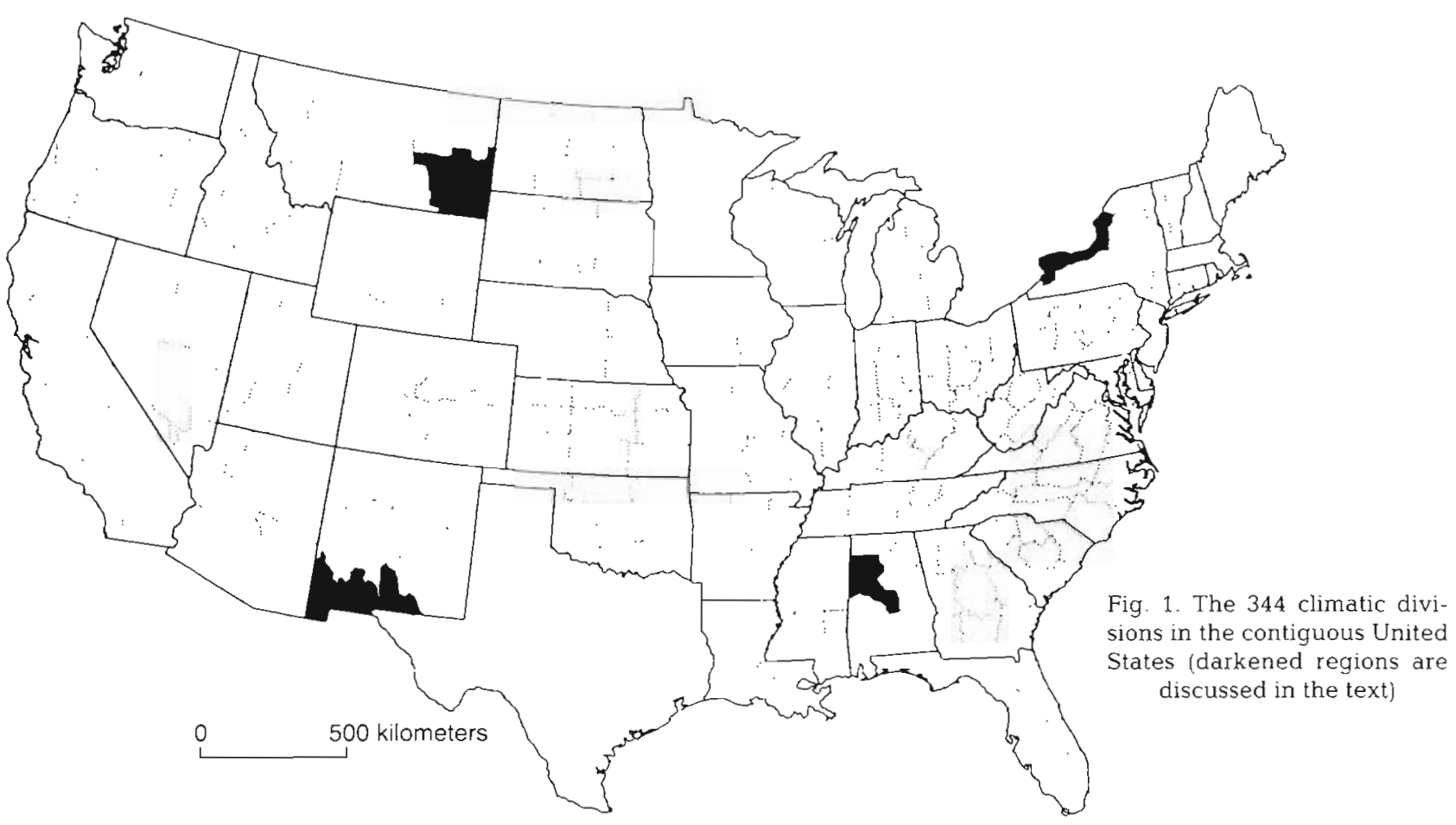

\section{DATA AND METHODS}

We used annual average values of the Palmer Hydrologic Drought Severity Index (PHDI) for each of the 344 climatic divisions in the contiguous United States for the period 1895 to 1989 (Fig. 1). Yin (1993) describes how the use of annual Palmer index data (Palmer 1965) is preferable over monthly data in trend analyses because it eliminates some problems typically associated with the Palmer indices, primarily bimodality and autocorrelation. Along with the Moisture Anomaly Index (ZINX) and Palmer Drought Severity Index (PDSI), the PHDI is one of the 3 Palmer drought severity indices used widely in examinations of United States drought conditions. The PHDI matches the regionally standardized supply of moisture with demand to form an index, based on the monthly water balance, that produces negative numbers when moisture conditions are below regional and monthly norms (i.e. drought), and positive numbers when abovenormal moisture conditions occur. Since it is standardized on zero, the greater the absolute PHDI value the more abnormal the monthly moisture conditions. In comparison to the ZINX and PDSI, the PHDI responds slowly to a changed moisture status. Thus, it emulates conditions in hydrologic systems and is considered a 'hydrologic drought' index.

We obtained all data from the National Climate Information Disc (National Climatic Data Center 1990). The PHDI data are calibrated over the period 1895 to 1989 (National Climatic Data Center 1990) and are reliable as this data set has been corrected for errors relating to observation time changes (Karl et al. 1986b). Interannual variability in the PHDI is mostly determined by interannual variability in precipitation. A warming trend may result in higher evapotranspiration rates and lower PHDI values. However, long-term trends resulting from temperature changes will likely be obscured by fluctuations in precipitation. Procedures used to calculate the Palmer indices are thoroughly detailed by Karl (1983) and Alley (1984).

We completed bivariate linear regressions for each climatic division using annual values of the PHDI as the dependent variable and calendar year as the explanatory variable. The use of bivariate regression to search for trends in climatic data sets is well established (e.g. Karl et al. 1986a, Karl \& Heim 1990, Plantico et al. 1990, Idso \& Balling 1992, Yin 1993). Trends are analyzed over 4 different time periods, (1) the complete 95 yr time series (1895 to 1989), (2) a 50 yr period that represents the post-dust bowl era (1940 to 1989), (3) a 30 yr period (1960 to 1989), and (4) a shorter, $15 \mathrm{yr}$ period (1975 to 1989). When used consistently across the 344 individual data sets, linear trend analysis provides one useful parameter, the trend slope, to help aid in the determination of temporal shifts in the moisture regime. Since climatic trends are seldom linear, the assumption of a linear relationship between a climatic parameter, such as PHDI, and time would be violated in a simple regression. Therefore, non-parametric methods, such as Spearman's rank correlation, have been recommended in testing the significance of 
trends (World Meteorological Organization 1986). The statistical significance of the trends is examined using a corresponding (to the slope analyses) series of Spearman rank correlations between PHDI and calendar year.

\section{RESULTS}

\section{5 yr analyses}

Spatial patterns of the linear trends in PHDI values over the complete data period (1895 to 1989) show slopes ranging from -0.057 in Upper Platte, Wyoming, to 0.048 in Northwest Plateau, Pennsylvania (Fig. 2a). This is equivalent to a $95 \mathrm{yr}$ change in PHDI values of -5.4 and 4.6, respectively. Significant (at $\alpha=0.05$ ) positive slopes, an indicator of a long-term change toward wetter conditions, are found in 4 core areas: (1) the eastern Great Lakes/northeastern Ohio Valley region (primarily western Pennsylvania and New York), (2) the south central Gulf region (primarily Alabama and Mississippi), (3) the north central Great Plains (centered in South Dakota), and (4) the coastal Pacific Northwest (Fig. 2b). One large core of significant negative trends is found in the north central Rocky Mountain and high plains region, with negative slopes maximized in Wyoming and eastern Colorado. Significant negative slopes are also found in the northeast, largely in climatic divisions bordering Canada (Maine to New York).

\section{0 yr analyses}

Spatial patterns of the linear trends in PHDI values over the period 1940 to 1989 are complex, particularly in the western United States (Fig. 3a). Multiple nodes of positive and negative slopes are evident. Negative slopes are again maximized in Wyoming, reaching -0.112 (-5.6 PHDI units) in the Wind River climatic division. Positive slopes are maximized in the Southeast Arizona climatic division, with a recorded slope of 0.111 (5.5 PHDI units). While there are no large con-
Fig. 2. (a) Spatial patterns of 95 yr (1895 to 1989) linear trend slopes (PHDI/year) from the series of bivariate regressions between annual PHDI values and time. (b) Significance levels ( $p$-values) from the corresponding series of Spearman rank correlation analyses between annual PHDI values and time

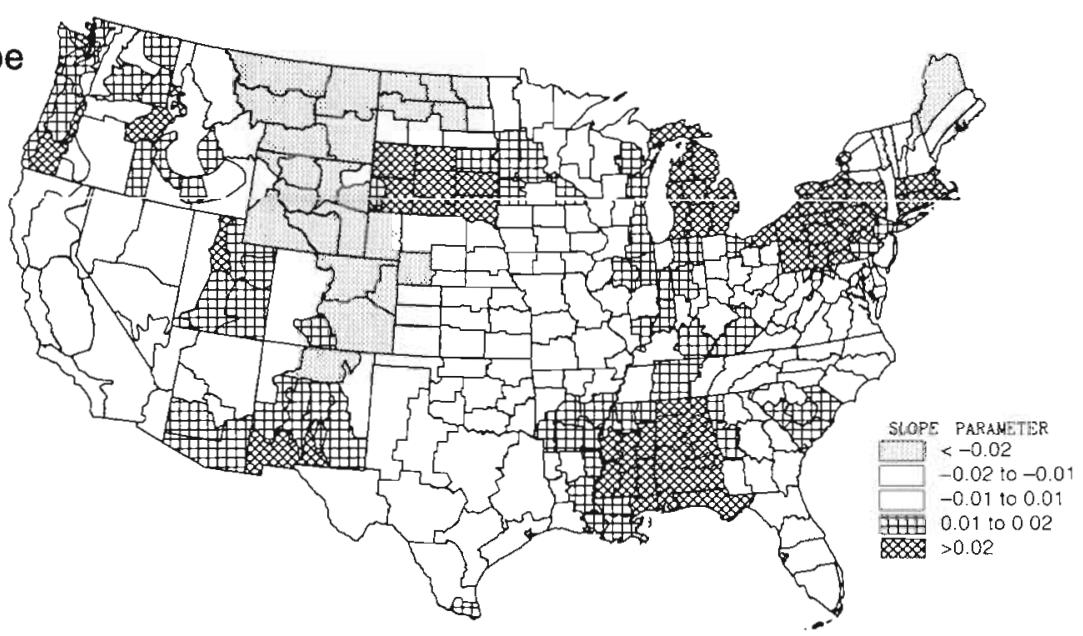

b) Significance

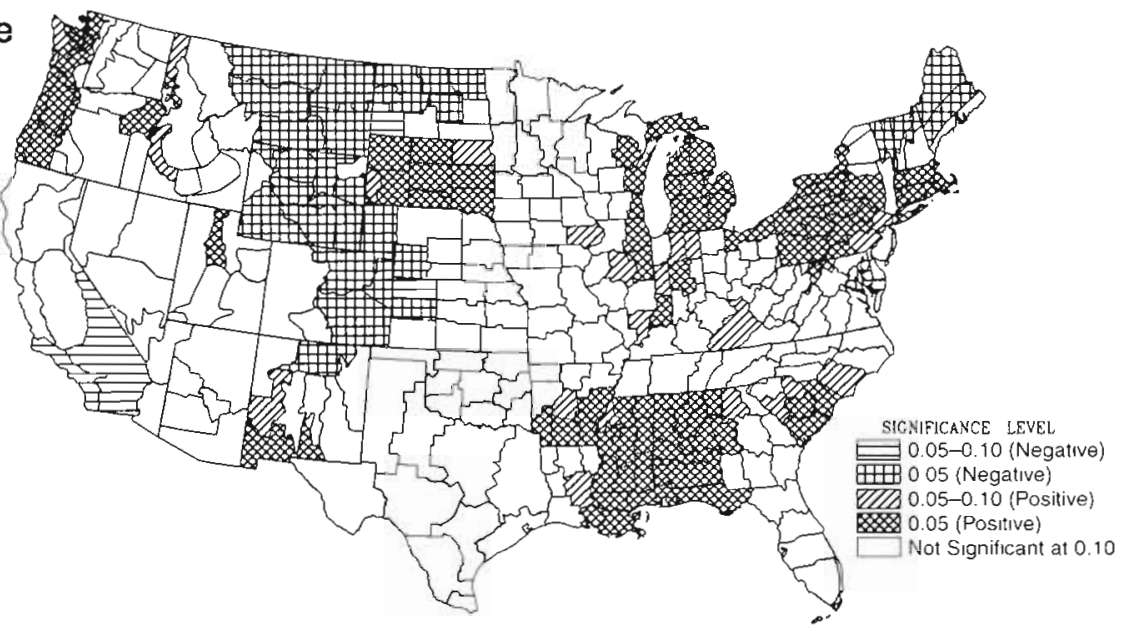




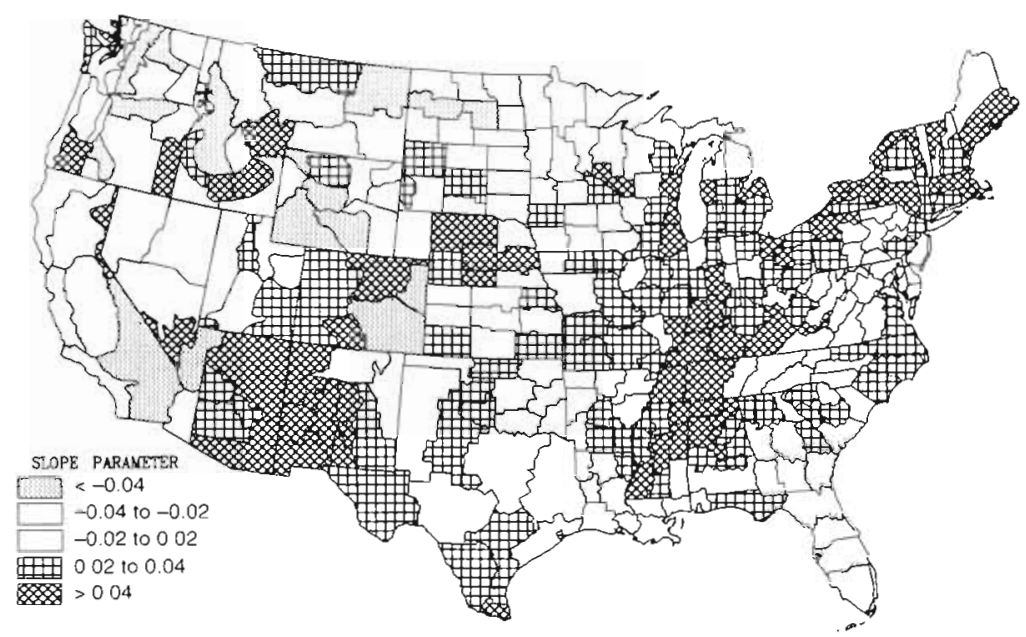

\section{a) Trend Slope}

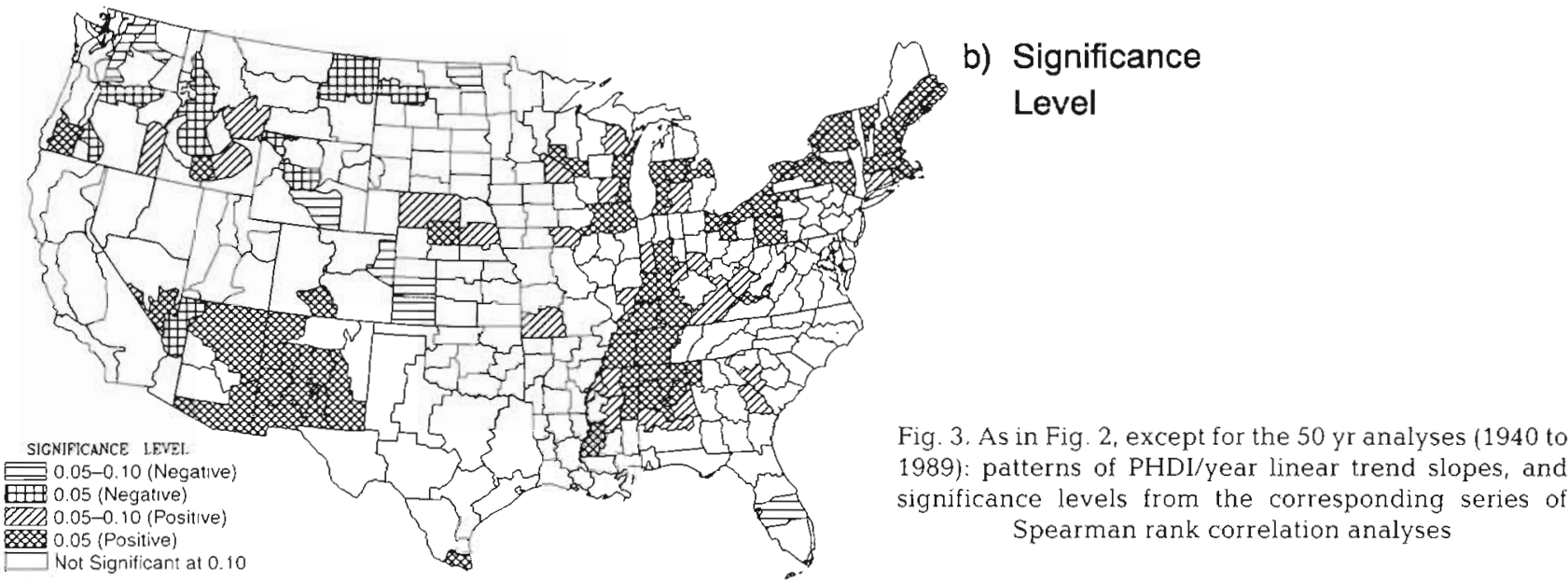

tiguous areas with significant negative slopes, clusters of climatic divisions with significant positive slopes are found in the southwest, the western Ohio Valley and Tennessee Valley region, and bordering the Great Lakes. Whereas the western states have a complex pattern with many adjacent areas of opposite slope, most of the eastern United States have either neutral or weakly positive slopes.

\section{0 yr analyses}

Positive slopes dominate throughout most of the United States, with areas of significant positive slopes found in the desert southwest (New Mexico, Arizona, and west Texas) and the eastern Great Lakes (portions of New York, Pennsylvania, Ohio, and Michigan adjacent to lakes Ontario, Erie, and Huron) (Fig. 4). The core area of strongest negative slopes is in the southern Atlantic coastal region, with a contiguous area of climatic divisions showing significant slopes centered in Georgia and South Caro- lina. The range in slope is from $-0.113(-3.4$ PHDI units) in the North Central, Georgia, climatic division to 0.181 (5.4 PHDI units) in the Northeast, Arizona, climatic division.

\section{5 yr analyses}

There are distinct directional patterns to the $15 \mathrm{yr}$ slopes (Fig. 5). Positive trends dominate throughout a large area of the central Great Plains, high plains, and Rocky Mountain states, with slopes maximized (0.325 $\mathrm{yr}^{-1}$ or 4.9 PHDI units) in the Northeastern Plains climatic division of New Mexico. However, the positive trends are only significant (at $\alpha=0.05$ ) at 7 climatic divisions. Negative trends are maximized $\left(-0.477 \mathrm{yr}^{-1}\right.$ or -7.2 PHDI units) in the South Central climatic division of Montana, the core of a large region of significant negative slopes in the northern high plains and Rocky Mountains. Negative slopes dominate east of the Mississippi, with significant trends found in climatic divisions from Alabama to New York. 
Significant negative slopes are also found in southern California and northwestern New Mexico.

\section{COMPARISON}

There are some distinct shifts in the trend patterns when comparing results from the 4 time series. Most noticeable is a shift from strong positive trends to negative trends in the southeastern United States. Although the positive $95 \mathrm{yr}$ slopes in the southeast (Fig. 2) support the findings of both Karl \& Heim (1990) and Yin (1993), the mapped patterns show that the most recent trends in most of the southeast are downward, especially during the 1975 to 1989 period (Fig. 5). This does not necessarily indicate a shift toward drought conditions in the southeast; it may simply imply a shift to more normal annual moisture conditions after the exceptionally wet years of the mid 1970s. This is illustrated by the PHDI time series for the Upper Plains, Alabama, climatic division (Fig. 6; see Fig. 1 for location).
Another large shift in trend is evident when comparing the most recent $15 \mathrm{yr}$ slopes with the 30,50, and 95 yr slopes in the regions immediately east of Lake Ontario and Lake Erie. Positive slopes are found in these regions for the longer time intervals (Figs. 2, 3 \& $4)$, but for the most recent interval the slope becomes negative (Fig. 5). As was the case in the southeast, a time series plot from the Great Lakes climatic division of New York (Fig. 7; see Fig. 1 for location) shows that the downward trend for the 15 yr period simply represents a return to more normal moisture conditions after the exceptionally wet period of the mid 1970 s.

The progression of slopes in the southwestern states is noteworthy. The 95 yr trends are neutral to weakly positive throughout most of the southwest (Fig. 2), but the 50 yr trends are strongly positive along the United States/Mexico border (Fig. 3). A times series plot from the Southern Desert climatic division of New Mexico illustrates the strong positive trend over the 1940 to 1989 period (Fig. 8; see Fig. 1 for location). The area of maximum positive slope shifts to the northeast for the 30 yr time series (Fig. 4), and a further northeastward
Fig. 4. As in Fig. 2, except for the $30 \mathrm{yr}$ analyses (1960 to 1989); patterns of PHDI/year linear trend slopes, and significance levels from the corresponding series of Spearman rank correlation analyses a) Trend Slope

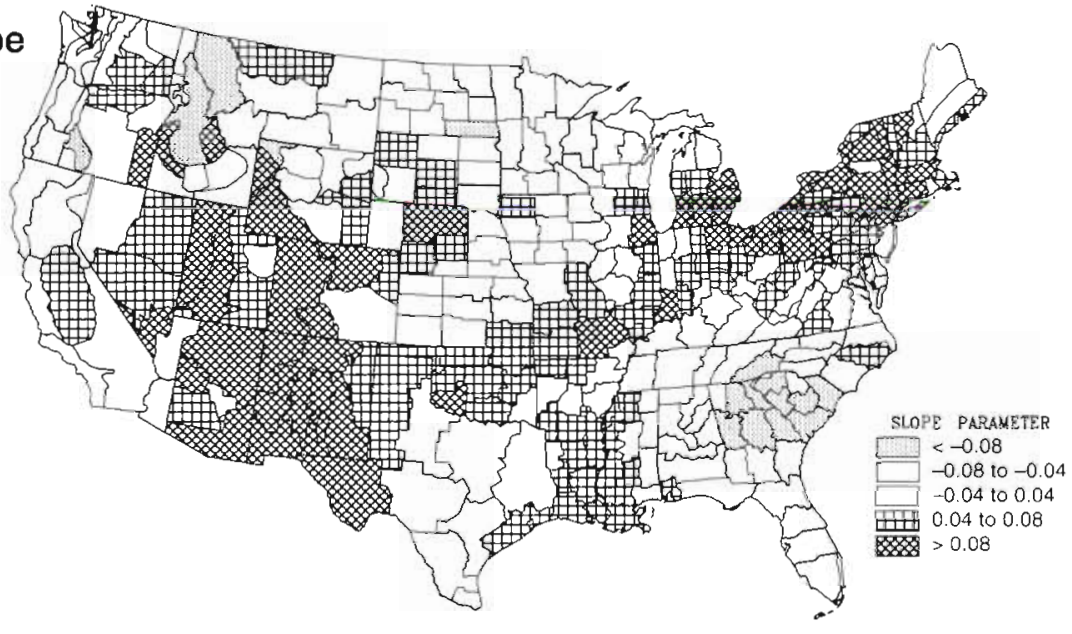

b) Significance Level

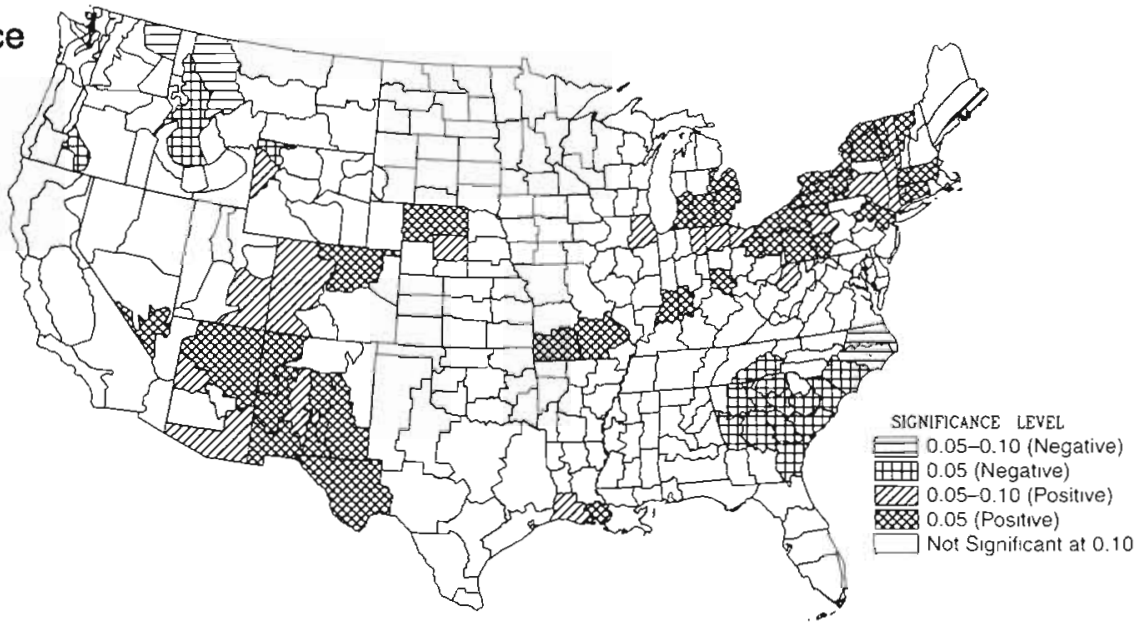




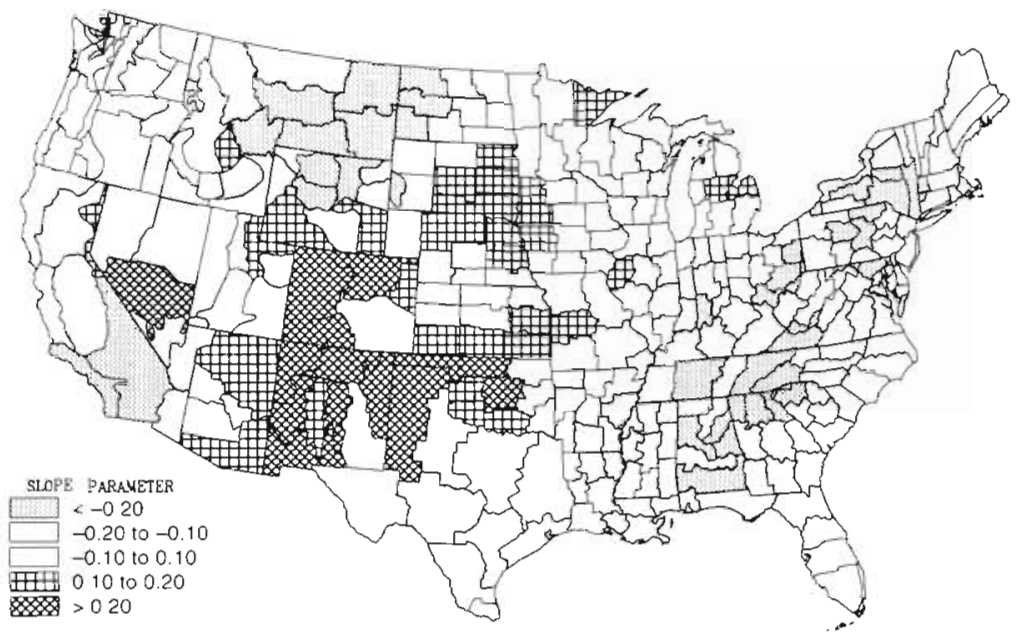

a) Trend Slope

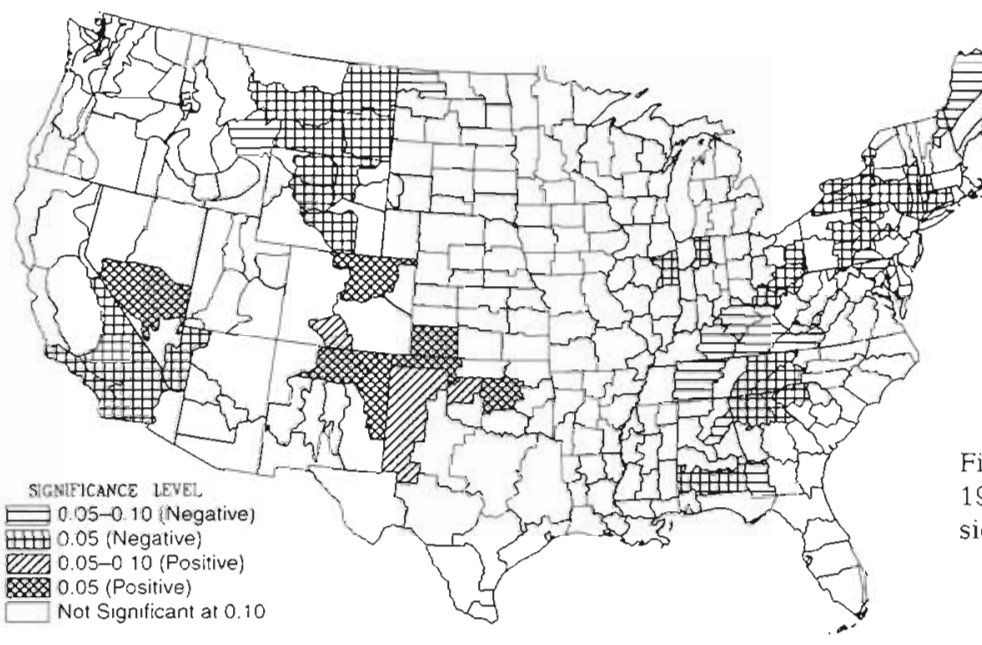

\section{b) Significance Level}

Fig. 5. As in Fig. 2, except for the 15 yr analyses (1975 to 1989): patterns of PHDI/year linear trend slopes, and significance levels from the corresponding series of Spearman rank correlation analyses

shift is evident on the 15 yr maps where the area of maximum positive slope is found near the Oklahoma panhandle (Fig. 5).

In the northern Great Plains (e.g. eastern Montana/western North Dakota), significant negative trends are found over the 95 and $15 \mathrm{yr}$ time series (Figs, 2 \& 5), but most climatic divisions record no significant trends over the 50 and 30 yr periods (Figs. 3 \& 4). A time series plot of annual PHDI values from the Southeastern climatic division of Montana shows a cyclic pattern of moisture in the middle time periods, with transitions from peak drier-than-normal to wetterthan-normal conditions taking approximately 10 to 20 yr (Fig. 9; see Fig. 1 for location). This tendency for both droughts and wet spells to persist for long periods of time in the United States interior has been documented by Diaz (1983), with further evidence of drought persistence in the interior supported by Karl \& Koscielny (1982), Walsh et al. (1982), Karl et al. (1987), and Soulé (1992)

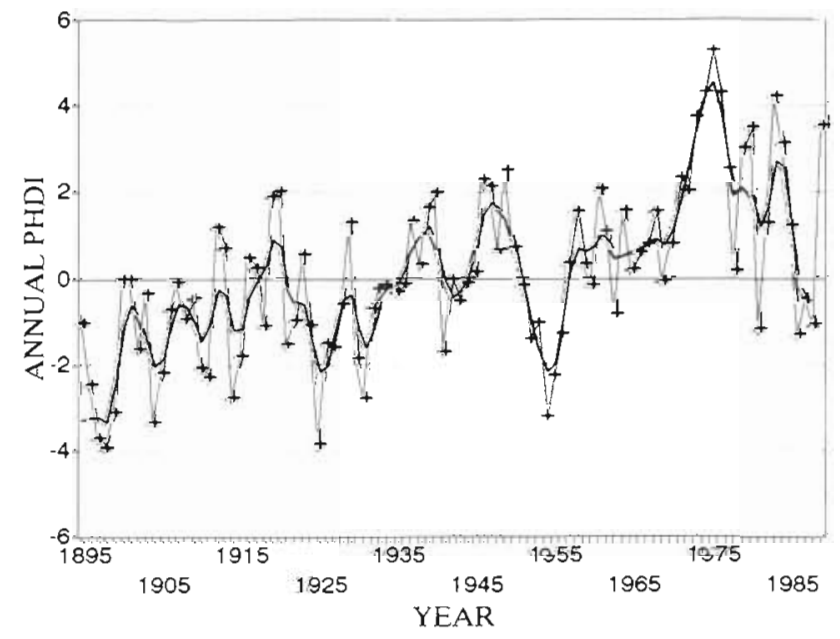

Fig. 6. Time series of annual PHDI values for the Upper Plains climatic division of Alabama (solid line is a weighted 5 yr lowpass filter] 


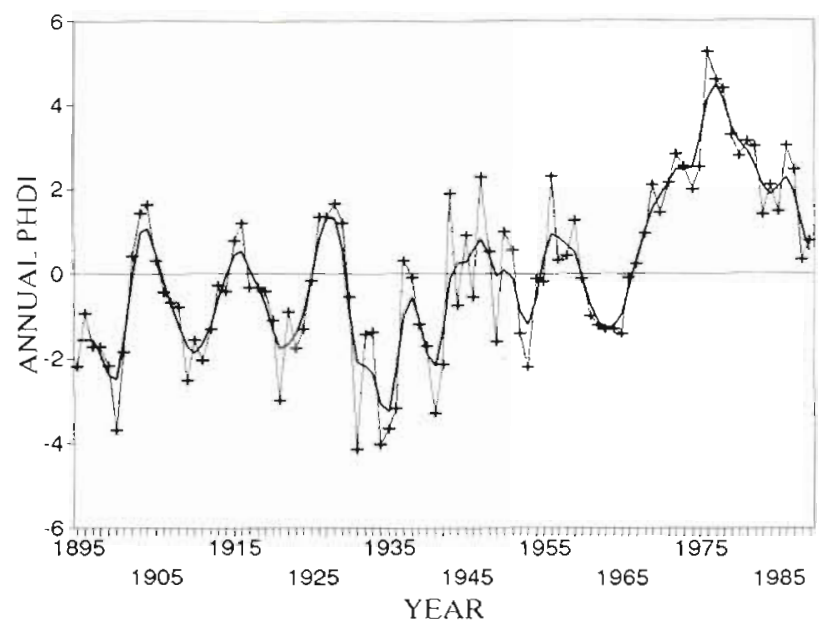

Fig. 7. Time series of annual PHDI values for the Great Lakes climatic division of New York (solid line is a weighted $5 \mathrm{yr}$ low-pass filter)

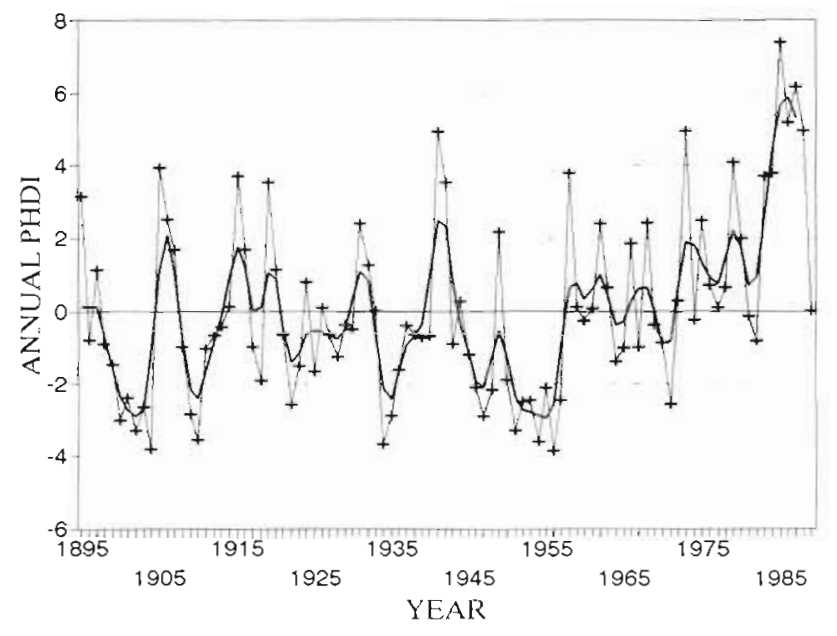

Fig. 8. Time series of annual PHDI values for the Southern Desert climatic division of New Mexico (solid line is a weighted 5 yr low-pass filter)

Table 1. Comparisons among the 4 time series. Upper right portion of the table shows the simple $r$ values from a spatial pattern correlation of slopes between time series $(n=344)$. Lower left portion of the table shows the number of directional changes in slope between different time periods

\begin{tabular}{|l|cccc|}
\hline $\begin{array}{l}\text { Time } \\
\text { series }\end{array}$ & $15 \mathrm{yr}$ & $30 \mathrm{yr}$ & $50 \mathrm{yr}$ & $95 \mathrm{yr}$ \\
\hline $\mathbf{1 5}$ & - & $0.33^{\circ}$ & 0.09 & 0.07 \\
$30 \mathrm{yr}$ & 165 & - & $0.45^{\circ}$ & $0.27^{\circ}$ \\
$50 \mathrm{yr}$ & 210 & 99 & - & $0.49^{\circ}$ \\
$95 \mathrm{yr}$ & 203 & 115 & 84 & - \\
& & & & \\
\hline
\end{tabular}

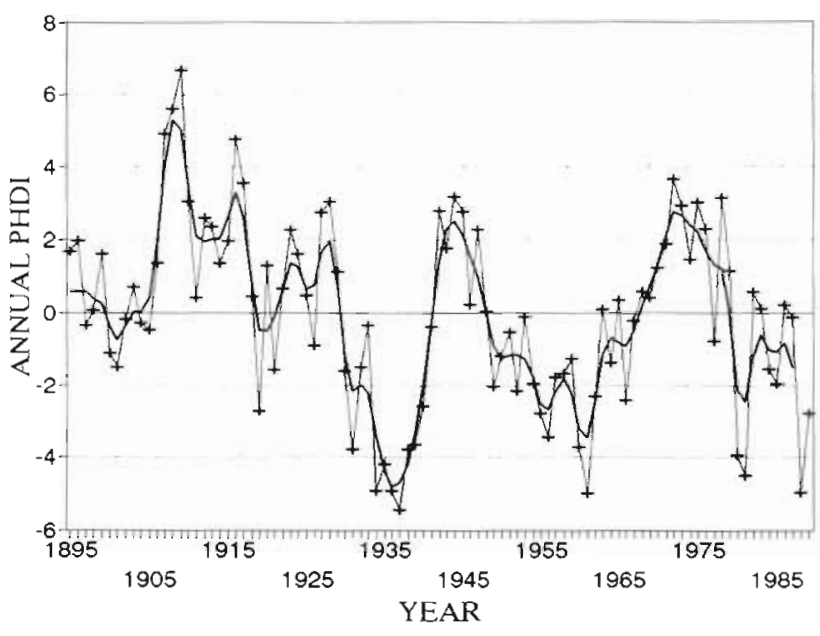

Fig. 9. Time series of annual PHDI values for the Southeastern climatic division of Montana (solid line is a weighted 5 yr lowpass filter)

An examination of slope trend relationships among the 4 time series shows that moderate positive correlations are found for all consecutive time series (e.g. $15 \mathrm{yr} / 30 \mathrm{yr}$ ), with the correlations increasing in strength as longer time series pairs (e.g. 50 yr/95 yr) are compared (Table 1). These correlations suggest that slope directions are somewhat stable for consecutive periods, particularly the longer periods. Further support of this finding is found by comparing the total number of directional slope changes between the 4 time series pairs (Table 1). The smallest number of directional changes in slope occurs between the 50 and 95 yr time series, the second smallest between the 30 and 50 yr periods. Although correlations between the 15 yr time series slopes and the longer intervals $(50 \mathrm{yr}$, 95 yr) are weakly positive, the relationships are clearly volatile, with approximately $60 \%$ of the climatic divisions experiencing a shift from a positive to negative or negative to positive trend.

Another means of comparison is to look at the raw numbers for slope direction for all climatic divisions (Table 2). For the full study period, 236 of the 344 $(69 \%)$ climatic divisions recorded positive slopes, and the mean slope relates to a nationwide shift of approximately 0.52 PHDI units over this period. The ratio of positively to negatively sloping trends increased in the 50 yr period with $76 \%$ of the climatic divisions recording positive slopes. The 50 yr slope for the entire U.S. also suggests a trend toward wetter conditions, with a gain of 0.76 PHDI units. For the 30 yr period, $68 \%$ of the climatic divisions recorded positive trends. The mean slope for this period corresponds to an increase of 0.76 PHDI units. A major shift occurred in the most recent 15 yr time series, with $69 \%$ of the climatic divi- 
Table 2. Regional slope comparisons: mean, standard deviation, and p-value for a Student's $t$-test of the means $\left(H_{0}\right.$ : mean slope $\left.=0\right)$. n: no. of climatic divisions

\begin{tabular}{|c|c|c|c|c|c|}
\hline Region & $\mathrm{n}$ & $\begin{array}{l}\text { Time } \\
\text { series }\end{array}$ & $\begin{array}{c}\text { Mean PHDI } \\
\text { slope }\end{array}$ & $\mathrm{SD}$ & $\begin{array}{l}\text { p-value } \\
\text { for } t \text {-test }\end{array}$ \\
\hline Nation & 344 & $\begin{array}{l}95 \mathrm{yr} \\
50 \mathrm{yr} \\
30 \mathrm{yr} \\
15 \mathrm{yr}\end{array}$ & $\begin{array}{r}0.0055 \\
0.0151 \\
0.0253 \\
-0.0568\end{array}$ & $\begin{array}{l}0.0175 \\
0.0295 \\
0.0557 \\
0.1394\end{array}$ & $\begin{array}{l}0.0001 \\
0.0001 \\
0.0001 \\
0.0001\end{array}$ \\
\hline 1 (Southeast) & 45 & $\begin{array}{l}95 \mathrm{yr} \\
50 \mathrm{yr} \\
30 \mathrm{yr} \\
15 \mathrm{yr}\end{array}$ & $\begin{array}{r}0.0109 \\
0.0156 \\
-0.0387 \\
-0.1386\end{array}$ & $\begin{array}{l}0.0138 \\
0.0197 \\
0.4551 \\
0.0969\end{array}$ & $\begin{array}{l}0.0001 \\
0.0001 \\
0.0001 \\
0.0001\end{array}$ \\
\hline 2 (Southwest) & 23 & $\begin{array}{l}95 \mathrm{yr} \\
50 \mathrm{yr} \\
30 \mathrm{yr} \\
15 \mathrm{yr}\end{array}$ & $\begin{array}{l}0.0053 \\
0.0305 \\
0.0832 \\
0.0524\end{array}$ & $\begin{array}{l}0.0134 \\
0.0488 \\
0.0560 \\
0.1879\end{array}$ & $\begin{array}{l}0.0692 \\
0.0066 \\
0.0001 \\
0.1947\end{array}$ \\
\hline 3 (South) & 52 & $\begin{array}{l}95 \mathrm{yr} \\
50 \mathrm{yr} \\
30 \mathrm{yr} \\
15 \mathrm{yr}\end{array}$ & $\begin{array}{l}0.0051 \\
0.0112 \\
0.0433 \\
0.0355\end{array}$ & $\begin{array}{l}0.0130 \\
0.0204 \\
0.0283 \\
0.0121\end{array}$ & $\begin{array}{l}0.0067 \\
0.0002 \\
0.0001 \\
0.0395\end{array}$ \\
\hline 4 (Central) & 59 & $\begin{array}{l}95 \mathrm{yr} \\
50 \mathrm{yr} \\
30 \mathrm{yr} \\
15 \mathrm{yr}\end{array}$ & $\begin{array}{r}0.0097 \\
0.0290 \\
0.0461 \\
-0.0952\end{array}$ & $\begin{array}{l}0.0099 \\
0.0155 \\
0.0409 \\
0.1009\end{array}$ & $\begin{array}{l}0.0001 \\
0.0001 \\
0.0001 \\
0.0001\end{array}$ \\
\hline 5 (Northwest) & 27 & $\begin{array}{l}95 \mathrm{yr} \\
50 \mathrm{yr} \\
30 \mathrm{yr} \\
15 \mathrm{yr}\end{array}$ & $\begin{array}{r}0.0092 \\
-0.0040 \\
-0.0074 \\
-0.0801\end{array}$ & $\begin{array}{l}0.0101 \\
0.0371 \\
0.0549 \\
0.1111\end{array}$ & $\begin{array}{l}0.0001 \\
0.5759 \\
0.4916 \\
0.0009\end{array}$ \\
\hline 6 (West) & 8 & $\begin{array}{l}95 \mathrm{yr} \\
50 \mathrm{yr} \\
30 \mathrm{yr} \\
15 \mathrm{yr}\end{array}$ & $\begin{array}{r}-0.0025 \\
0.0132 \\
0.0412 \\
-0.0144\end{array}$ & $\begin{array}{l}0.0076 \\
0.0298 \\
0.0407 \\
0.0841\end{array}$ & $\begin{array}{l}0.3825 \\
0.2503 \\
0.0243 \\
0.6425\end{array}$ \\
\hline $\begin{array}{l}7 \text { (West-North } \\
\text { Central) }\end{array}$ & 46 & $\begin{array}{l}95 \mathrm{yr} \\
50 \mathrm{yr} \\
30 \mathrm{yr} \\
15 \mathrm{yr}\end{array}$ & $\begin{array}{r}-0.0105 \\
-0.0025 \\
0.0087 \\
-0.0624\end{array}$ & $\begin{array}{l}0.0265 \\
0.0394 \\
0.0528 \\
0.1902\end{array}$ & $\begin{array}{l}0.0103 \\
0.6714 \\
0.2677 \\
0.0312\end{array}$ \\
\hline 8 (Northeast) & 47 & $\begin{array}{l}95 \mathrm{yr} \\
50 \mathrm{yr} \\
30 \mathrm{yr} \\
15 \mathrm{yr}\end{array}$ & $\begin{array}{r}0.0079 \\
0.0211 \\
0.0594 \\
-0.1358\end{array}$ & $\begin{array}{l}0.0213 \\
0.0232 \\
0.0403 \\
0.0704\end{array}$ & $\begin{array}{l}0.0134 \\
0.0001 \\
0.0001 \\
0.0001\end{array}$ \\
\hline $\begin{array}{l}9 \text { (East-North } \\
\text { Central) }\end{array}$ & 37 & $\begin{array}{l}95 \mathrm{yr} \\
50 \mathrm{yr} \\
30 \mathrm{yr} \\
15 \mathrm{yr}\end{array}$ & $\begin{array}{l}0.0081 \\
0.0172 \\
0.0060 \\
0.0217\end{array}$ & $\begin{array}{l}0.0138 \\
0.0191 \\
0.0415 \\
0.0842\end{array}$ & $\begin{array}{l}0.0009 \\
0.0001 \\
0.3810 \\
0.1253\end{array}$ \\
\hline
\end{tabular}

tially coherent drought regions in the contiguous United States. Using their regional breakdown, we examined mean slope conditions and the significance of these slopes for 9 regions (Fig 10). The data support our finding of a high degree of intra-regional homogeneity in the drought patterns (Table 2). For the 95 yr patterns, $t$-tests show that slopes for 7 of the 9 regions are statistically different from zero $(\alpha=0.05)$ (Table 2). For the 50, 30, and 15 yr comparisons, 6 of 9 regional slopes are significant. In addition, the direction of these regional mean slopes is consistent with our findings. Most regions record positive slopes for the 95,50 and $30 \mathrm{yr}$ periods ( 7 of 9 regions in all cases), while negative slopes dominate in the $15 \mathrm{yr}$ period (6 of 9 regions).

\section{CONCLUSIONS}

For the United States as a whole, the positive $95 \mathrm{yr}$ trends in annual PHDI values (i.e. a shift toward more normal or above normal moisture conditions) agree with Karl \& Heim's (1990) finding that the contiguous United States has not undergone a substantial trend toward drought conditions this century. The positive 50 and $30 \mathrm{yr}$ trends also support Idso \& Balling's (1992) finding of a significant trend toward wetter conditions in the post-1954 period. However, the shorter-term (15 yr) patterns show that many areas have experienced a recent directional change (positive to negative) in slope, reflecting a return to more normal moisture or drought conditions. A shift

sions recording negative slopes. The mean slope for the 15 yr period suggests a decrease of 0.85 PHDI units. Using t-tests, national mean slopes for the 4 periods were significantly different from zero at $\alpha=$ 0.05 (Table 2).

The trend slope maps (Figs. 2 to 5) show a high degree of regional homogeneity in trends, especially at the longer intervals. These patterns led us to speculate how often the trends would be statistically significant for predetermined regional agglomerations of climatic divisions. Karl \& Koscielny (1982) used the PSDI and rotated principal components analysis to identify spa- toward drought conditions would be disadvantageous to agricultural activities in the affected regions. The term slope patterns shows that perceptions of trends toward drier or wetter conditions are largely dependent on the temporal scaling.

Perceptions of moisture trends can also be scale dependent. While mean trends for the United States are positive for the 95,50 , and 30 yr periods and negative for the $15 \mathrm{yr}$ period, there are distinct homogeneous regions of significant positive and negative trends for each period. Regional-scale trends may have a stronger influlack of agreement between the shorter-and longer- 


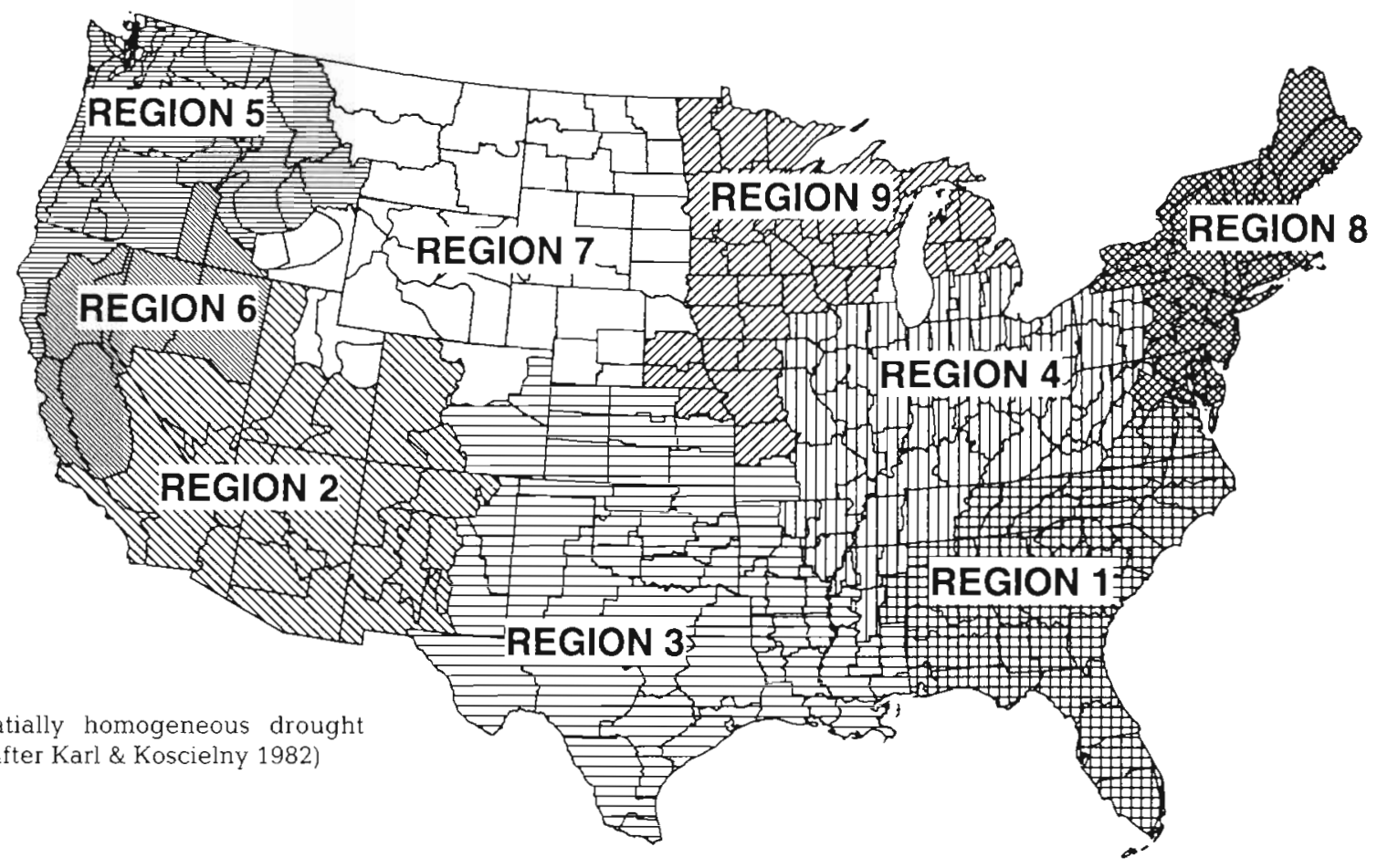

ence on a person's perception of how the moisture climate of the United States has changed through time than national-scale trends. Since most drought planning is a regional endeavor, information on how their region has bchaved (including trends and intra-regional variability) in recent climatic history is useful for those involved in drought contingency planning.

\section{LITERATURE CITED}

Alley WM (1984) The Palmer Drought Severity Index: limitations and assumptions. J Clim appl Meteorol 23: 1100-1109

Diaz HF (1983) Some aspects of major dry and wet periods in the contiguous United States, 1895-1981 J Clim appl Meteorol 22:3-16

Idso SB, Balling RC Jr (1992) United States drought trends of the past century. Agricult For Meteorol 60:279-284

Karl TR (1983) Some spatial characteristics of drought duration in the United States. J Clim appl Meteorol 22:1356-1366

Karl TR, Heim RR Jr (1990) Are droughts becoming more frequent or severe in the United States? Geophys Res Lett 17 : 1921-1924

Karl TR, Koscielny AJ (1982) Drought in the United States: 1895-1981. J Climatol 2:313-329

Karl TR, Kukla G, Gavin J (1986a) Relationship between decreased temperature range and precipitation trends in the United States and Canada, 1941-80. J Clim appl Meteorol 25:1878-1886

Editor: V. Meentemeyer, Athens, Georgia, USA
Karl R, Quinlan F, Ezell DS (1987) Drough terminiation and amelioration: its climatological probability. J Clim appl Meterol 26:1198-1209

Karl TR, Williams CN Jr, Young PJ, Wendland WM (1986b) A model to estimate the time of observation bias associated with monthly mean maximum, minimum, and mean temperatures for the United States. J Clim appl Meteorol 25: $145-160$

National Climatic Data Center (1989) National Climate Information Disc, Vol 1. National Climatic Data Center, Asheville, NC

Palmer WC (1965) Meteorological drought. Res Pap No 45, US Weather Bureau, Washington, DC

Plantico MS, Karl TR, Kukla G, Gavin J (1990) Is recent climate change across the united states related to rising levels of anthropogenic greenhouse gases? J geophys Res 95:16617-16637

Soule PT (1992) Spatial patterns of drought frequency and duration in the contiguous usa based on multiple drought event definitions. Int J Climatol 12:11-24

Soulé PT (1993) Hydrologic drought in the contiguous United States, 1900-1989: spatial patterns and multiple comparison of means. Geophys Res Lett 20:2367-2370

Walsh JE, Richman MB Allen DW (1982) Spatial coherence of monthly precipitation in the United States. Mon Weather Rev 110:272-286

World Meteorological Organization (1986) Climatic change: technical note no 79. World Meteorological Organization, Geneva

Yin ZY (1993) Spatial pattern of temporal trends in moisture conditions in the southeastern United States. Geograf Annal Ser A 75:1-11

Manuscript first received: August 1, 1994 Revised version accepted: January 20, 1995 